\title{
Take a Look at the Main Impacts of Agricultural Land Use Change in Iran
}

\author{
A. Asadi, A. A. Barati, and K. Kalantari
}

\begin{abstract}
Land Use and Cover Change (LUCC), especially, Agricultural Land Use Change (ALC) as a result of human activities over the past 50 years, is converted to a main challenge of 21 century. This is especially important because of its direct relations with issues such as food security and environmental sustainability. According to the 2012 FAO report, the per capita of arable land in the world declines $1.46 \%$ from 1970 to 2009. This decrease for Iran has been $\mathbf{2 . 0 5 4 \%}$. It represents that ALC in Iran is worse than the most of the other areas of the world. The main object of this study was determining the effects or impacts of ALC in Iran. The study group consisted of the executive officers and policy makers who were working in Agricultural Lands Organizations and Administrations in 2012. For data collection a questionnaire which was completed with interview method was used. The numbers of interviewees were 101 persons. The collected data were analyzed using descriptive statistical and factor analysis (FA) methods. This study showed, among the main economic, social and environmental impacts of ALC, "increasing the land price as a result of ALC", "motivate the other farmers to ALC" and "increasing the energy consumption per unit area" respectively had been the most important impacts. But, based on the FA method, the most effective impacts of ALC were "increase the risk of rural households' income", "increased the uninhabited villages" and "reduces the air quality".
\end{abstract}

Index Terms-Agricultural lands, impacts, Iran, land use changes.

\section{INTRODUCTION}

\section{A. Land Use Changes and Its Challenges}

The problems associated with land, water and air are the major challenges facing humanity in the 21 st century [1], [2]. Unreasonable and unsustainable exploitation of these resources facing human with diverse challenges such as climate change or emitting and storing greenhouse gases which will led to many problems such as decline in agricultural production and increasing hunger, disease and malnutrition [3]. Now, on over 40 percent of the Earth's ice-free land surface transformed [4].

Although this global environmental change has many interacting components, land use/land cover change (LUCC) or land conversion probably represents the most important factor affecting ecological systems [5]-[8]. Among the various types of land conversions, ALC is the most important one. Uncontrolled agricultural land conversion (ALC) has great impacts on the environment in general and agricultural products in particular. ALC is a phenomenon that is almost

Manuscript received May 4, 2014; revised September 5, 2014.

The authors are with the Department of Agricultural Development \& Management, Faculty of Agricultural Economics \& Development, College of Agriculture \& Natural Resources, University of Tehran, Iran (e-mail: aasadi@ut.ac.ir) unavoidable during economic development and population growth periods [9]. The importance of ALC is not only because it currently has the biggest transformative power on the earth [10] but also because in the last 50 years, several regions of the world have seen cropland areas stabilize, and in some areas, there has even been a decrease [11]. For example, according to the 2012 and 2013 edition of the FAO Statistical Yearbook, during 1970-2009 Iran arable land per person has decreased $2.1 \%$ [1], [12]. While, based on reports of the Statistical Center of Iran (SCI) agriculture is one of the most important sectors of Iran's economy, the sector currently constitutes $10 \%$ of the country's GDP and $19 \%$ of total employment. Agricultural products form about $30 \%$ of Iran's non-oil exports [13]. As FAO [12] has reported, Iran ranks amongst the top seven countries in producing 22 important agricultural products [14]. In recent years, the pace of change in agricultural lands to non-agricultural lands is intensifying in the country. Now the lands are fragmented and crumbling. This process has intensified ALC. Apparently, so far not only have all the government policies and plans failed to control ALC, but some of them have exacerbated it [15].

\section{B. Land Use Changes Impacts}

Although in recent years, the studies which attended to the causes of land use change have been many [16]-[24] and these causes are well known, but its effects or impacts and especially socio-economic impacts are still mostly unknown. Then, studies in this scope are just beginning and little. Which some of them are mentioned in the following.

Mahoney [25] and Mudgal [26], for example, believed that the impacts of land use changes have environmental, social and economic aspects. But Scholte et al. [27], Barca [28] and Ronneberger et al. [29] have divided these to environmental and socio-economic impacts. Some environmental impacts are reduced biodiversity, reduced quantity and quality of air, water and soil, changes in the global carbon cycle, increase energy consumption, forest degradation, increasing the number of environmental disasters and their severity, increases greenhouse gases emission and raising the global temperature. Change the level of employment and unemployment, income, demographic changes (population, age pyramid, population density, etc.), food security and health, poverty, rising crime, health and social security, immigration, change the investment levels, change in agricultural and livestock products, and change the land prices are the main social and economic impacts of ALC and LUCC [30]-[34].

\section{Objectives and Structure of the Paper}

This study examines the main Impacts of ALC in Iran. For this aim, at first, the methodology of the paper is described. Second, the results are explained. Third, the research findings 
are discussed. Finally, a conclusion is drawn with regard to the main findings of this study.

\section{Methodology}

This study benefitted from a mixed-method approach that included both qualitative and quantitative measurements. Data were collected among executive officers and policy makers.

During the first stage and after a literature review, four policy makers and four executive officers were interviewed extract their opinion about the main impacts of ALC using the Delphi technique [35] and a focus group interview [36]. Over this stage totally 23 indicators or impacts were identified. Then, these identified impacts were classified in three main groups [25], [26] (economic, social and environmental) and were structured within a questionnaire. Afterward, the questionnaire was pre-tested. Finally, the final questionnaire was sent to selected executive officers and policy makers. They were asked to express their opinion in relation to each factors (impacts) of ALC by selecting a score from one to five ( 1 for not, 2 for little, 3 for somewhat, 4 for large and 5 for great impact of ALC). Total policy makers and executive officers were 135 persons that 101 persons randomly were selected.

The sample size is calculated based on Solvin's formula [37], [38], as follow:

$$
n=N /(1+N \times e \times e)
$$

where $n$ is sample size, $N$ is population and $e$ is percentage of imprecision of sampling that can be tolerated $(5 \%)$. The sample was therefore estimated as below:

$$
n=135 /(1+135 \times 0.05 \times 0.05)=100.93 \approx 101
$$

The methods of data analysis used in this study were Coefficient of Variation (CV) and Factor Analysis (FA) using the LISREL software V.8.8 [39] and SPSS.

\section{RESULTS}

\section{A. Explain the Main Impacts of ALC without Emphasis on Their Interactions with Each Other}

Table I shows the interviewees' views about the main economic, social and environmental impacts of ALC. It should be noted that in this table has been assumed there are no correlation between the variables. For this purpose, coefficient of variation was used. It represents among the three main groups of ALC impacts, respectively, economic, social and environmental impacts (with $0.31,0.35$ and 0.37 of coefficients of variation) were the most important impacts of ALC.

Based on Table I, three main economic impacts of ALC respectively were "Increasing the land price as a result of ALC", "Reducing crop yields" and "Reducing the income of rural households". Among the social impacts of ALC, three main impacts were "Motivate the other farmers to ALC", "The loss of rural lifestyle and traditions" and "Reducing of food security". Finally, as mentioned by interviewees "Increasing the energy consumption per unit area", "Reduce the quantity and quality of water and soil resources" and "Destroy the natural and rural landscapes" are three main important environmental impacts of ALC (see Table I).

TABLE I: THE MAIN IMPACTS OF ALC AND THEIR IMPORTANCE

\begin{tabular}{|c|c|c|c|c|}
\hline Effects (Impacts) & Symbol & Mean & SD & $\mathrm{CV}$ \\
\hline $\begin{array}{l}\text { Increasing the land price as a result of } \\
\text { ALC }\end{array}$ & EcoE4 & 4.37 & 0.78 & 0.18 \\
\hline Reducing crop yields & EcoE2 & 3.57 & 1.14 & 0.32 \\
\hline $\begin{array}{l}\text { Reducing the income of rural } \\
\text { households }\end{array}$ & EcoE1 & 3.31 & 1.06 & 0.32 \\
\hline $\begin{array}{l}\text { Reducing the number of income } \\
\text { sources of rural households and } \\
\text { thereby increase the risk of incomes }\end{array}$ & EcoE6 & 3.18 & 1.06 & 0.33 \\
\hline $\begin{array}{l}\text { Undermining the natural and rural } \\
\text { tourism }\end{array}$ & EcoE5 & 3.45 & 1.15 & 0.33 \\
\hline Increase in rural unemployment & EcoE3 & 3.14 & 1.21 & 0.38 \\
\hline Total Economic Effects & EcoE & 3.05 & 1.07 & 0.31 \\
\hline Motivate the other farmers to ALC & SociE6 & 3.83 & 1.07 & 0.28 \\
\hline Loss of rural lifestyle and traditions & SociE4 & 3.5 & 0.93 & 0.29 \\
\hline Reducing of food security & SociE7 & 3.75 & 0.95 & 0.29 \\
\hline $\begin{array}{l}\text { change the demographic of rural } \\
\text { communities (gender composition, } \\
\text { age pyramid, population density) }\end{array}$ & SociE2 & 3.14 & 1.18 & 0.31 \\
\hline Increase uninhabited villages & SociE8 & 3.16 & 1.03 & 0.34 \\
\hline $\begin{array}{l}\text { Increase migration from rural to } \\
\text { urban }\end{array}$ & SociE9 & 2.98 & 1.19 & 0.36 \\
\hline Increase rural poverty & SociE1 & 2.98 & 1.18 & 0.40 \\
\hline $\begin{array}{l}\text { Reduce physical and mental health of } \\
\text { rural households }\end{array}$ & SociE3 & 2.89 & 1.19 & 0.41 \\
\hline $\begin{array}{l}\text { Increase rural and urban crime and } \\
\text { violence }\end{array}$ & SociE5 & 2.77 & 1.27 & 0.46 \\
\hline Total Social Effects & SociE & 3.22 & 1.11 & 0.35 \\
\hline $\begin{array}{l}\text { Increasing the energy consumption } \\
\text { per unit area }\end{array}$ & EnviE6 & 3.45 & 1.03 & 0.30 \\
\hline $\begin{array}{l}\text { Reduce the quantity and quality of } \\
\text { water and soil resources }\end{array}$ & EnviE5 & 3.51 & 1.09 & 0.31 \\
\hline $\begin{array}{l}\text { Destroy the natural and rural } \\
\text { landscapes }\end{array}$ & EnviE8 & 3.70 & 1.32 & 0.36 \\
\hline Reduce the air quality & EnviE4 & 3.4 & 1.23 & 0.36 \\
\hline Increase the area temperature & EnviE3 & 3.05 & 1.19 & 0.39 \\
\hline Loss of biodiversity & EnviE1 & 3.21 & 1.27 & 0.40 \\
\hline $\begin{array}{l}\text { Increase emission of greenhouse } \\
\text { gases }\end{array}$ & EnviE2 & 3.12 & 1.28 & 0.41 \\
\hline $\begin{array}{l}\text { Increase frequency and severity of } \\
\text { environmental disasters }\end{array}$ & EnviE7 & 3.01 & 1.39 & 0.46 \\
\hline Total Environmental Effects & EnviE & 3.31 & 1.23 & 0.37 \\
\hline
\end{tabular}
ACCORDING TO INTERVIEWEES' VIEW

TABLE II: THE OUTPUT OF KMO AND BARTLETT'S TEST

\begin{tabular}{lcccc}
\hline \multirow{2}{*}{ Group } & \multirow{2}{*}{ KMO } & \multicolumn{3}{c}{ Bartlett's Test of Sphericity } \\
\cline { 3 - 5 } & & Chi-Square & df & Sig. \\
\hline EcoE. & 0.602 & 84.631 & 15 & 0.000 \\
SociE. & 0.767 & 293.09 & 36 & 0.000 \\
EnviE. & 0.901 & 392.25 & 28 & 0.000 \\
\hline \hline
\end{tabular}

\section{B. Explain the Main Impacts of ALC with Emphasis on Their Interactions with Each Other}

When we used coefficients of variation method, actually, we ignore the interactions among the variables. But in the real world these variables have interactions with each other. Then, in this section we analyzed these impacts using factor analysis method. This method helped us to consider also these relationships.

Table II indicates the results of Kaiser-Meyer-Olkin 
measure of sampling adequacy test (KMO) and Bartlett's test of sphericity. According to estimated parameters, our data were suitable for factor analysis test.

As shows in Table III, the three most effective of economic impacts of ALC, respectively, were "reducing the number of income sources of rural households and thereby increase the risk of incomes" (EcoE6), "increase rural unemployment" (EcoE3) and "reducing the income of rural households" (EcoE). These variables together explained $71 \%$ of total economic impacts variance.

TABLE III: THE OUTPUT OF FACTOR ANALYSIS THE CHNIQUE

\begin{tabular}{lccc}
\hline \hline Factors & $\begin{array}{c}\text { Factor } \\
\text { loading }\end{array}$ & $\begin{array}{c}\text { Eigen } \\
\text { values }\end{array}$ & $\begin{array}{c}\text { \% of variance which } \\
\text { explained }\end{array}$ \\
\hline EcoE6 & 0.729 & 2.283 & 38.046 \\
EcoE3 & 0.713 & 1.058 & 17.637 \\
EcoE1 & 0.682 & 0.919 & 15.317 \\
EcoE2 & 0.646 & 0.823 & 13.709 \\
EcoE5 & 0.446 & 0.559 & 9.319 \\
EcoE4 & 0.401 & 0.358 & 5.972 \\
\hline SociE8 & 0.790 & 3.989 & 44.326 \\
SociE4 & 0.789 & 1.335 & 14.832 \\
SociE3 & 0.776 & 1.072 & 11.912 \\
SociE5 & 0.716 & 0.687 & 7.630 \\
SociE1 & 0.683 & 0.583 & 6.476 \\
SociE2 & 0.630 & 0.507 & 5.632 \\
SociE7 & 0.569 & 0.365 & 4.055 \\
SociE9 & 0.486 & 0.251 & 2.793 \\
SociE6 & 0.455 & 0.211 & 2.344 \\
\hline EnviE4 & 0.893 & 5.062 & 63.275 \\
EnviE3 & 0.862 & 0.728 & 9.104 \\
EnviE2 & 0.831 & 0.670 & 8.371 \\
EnviE7 & 0.802 & 0.444 & 5.554 \\
EnviE8 & 0.786 & 0.399 & 4.985 \\
EnviE5 & 0.756 & 0.279 & 3.486 \\
EnviE6 & 0.719 & 0.245 & \\
EnviE1 & 0.694 & 0.173 & \\
\hline \hline Extraction & & Princ & \\
\hline
\end{tabular}

Extraction Method: Principal Component Analysis

Among the social impacts, "increase uninhabited villages" (SociE8), "loss of rural lifestyle and traditions" (SociE4) and "reduce physical and mental health of rural households" (SociE3) were the most effective. They are together explaining about $71 \%$ of total social impacts variance.

Finally, for environmental impacts, "reduce the air quality" (EnviE4), "increase the area temperature" (EnviE3) and "increase emission of greenhouse gases" (EnviE4) are the main environmental impacts of ALC. Totality, these three impacts, explain over than $80 \%$ of whole variance of ALC environmental impacts.

Although, according to interviewees' views the most important economic effects of ALC has been "accelerate the raising of the land price" (EcoE4), but based on FA of ALCEs "reducing the number of rural households' income sources and increase the risk of rural households' income" (EcoE6) is the most effective economic impacts of ALC. For social impacts, the most important impact has been "motivated the other farmers to ALC" (SociE6), but the most effective impact has been "increased the uninhabited villages" (SociE8). Finally, among the environmental impacts of ALC "increasing the energy consumption per unit area" (EnviE6) and "reduce the air quality" (EnviE4) orderly has been the most important and the most effective impacts.
As a result, although, according to executive officers and policy makers' views, the most important of economic, social, environmental impacts of ALC have been EcoE4, SociE6 and EnviE6, but if the planners and policy makers want to reduce the impacts of ALC, their attention should be given more to the following variables or impacts,

1) increase the risk of rural households income,

2) increased the uninhabited villages, and

3) reduce the air quality

Undoubtedly, due to the covariance among the various variables, pay appropriate attentions to these variables will facilitate dealing with the ALC impacts.

\section{CONCLUSION}

This paper aimed to analyzing the impacts of ALC in Iran base on the views of the executive officers and policy makers. It showed, the most important economic, social and environmental impacts of ALC respectively have been "accelerate the raising of the land price", "motivated the other farmers to ALC" and "increasing the energy consumption per unit area". But, the most effective impacts have been "increase the risk of rural households' income", "increased the uninhabited villages" and "reduce the air quality". Therefore, it is recommended that the planners and policy makers pay more attention to these impacts. Because, these impacts compared with the others, have a more cross-correlation with the other impacts.

\section{REFERENCES}

[1] FAO, FAO Statistical Yearbook 2012, Rome: FAO, 2012.

[2] FAO, The State of the World's Land and Water Resources for Food and Agriculture, Rome: FAO, 2011.

[3] The World Bank, World development report 2010: Development and climate change, Washington DC: The International Bank for Reconstruction and Development, 2010.

[4] J. A. Foley, R. DeFries, G. P. Asner et al., "Global consequences of land use," Science, vol. 309, no. 5734, pp. 570-574, 2005.

[5] P. Mondal and J. Southworth, "Evaluation of conservation interventions using a cellular automata-Markov model," Forest Ecology and Management, vol. 260, no. 10, pp. 1716-1725, 2010.

[6] B. L. Turner II, "Toward integrated land-change science: Advances in 1.5 decades of sustained international research on land-use and land-cover change," in Challenges of a Changing Earth: Proceedings of the Global Change Open Science Conference, W. Steffan, J. Jäger, D. Carson, and C. Bradshaw Eds. Amsterdam, NL, Springer-Verlag, Heidelberg, GR., 2002, pp. 21-26.

[7] B. L. Turner II, "Land change science," in International Encyclopedia of Human Geography, K. Rob and T. Nigel, Eds. Oxford: Elsevier, 2009, pp. 107-111.

[8] P. M. Vitousek, H. A. Mooney, J. Lubchenco, and J. M. Melillo, "Human domination of earth's ecosystems," Science, vol. 277, no. 5325, pp. 494-499, 1997.

[9] R. Tan, V. Beckmann, L. van den Berg, and F. Qu, "Governing farmland conversion: Comparing China with the Netherlands and Germany," Land Use Policy, vol. 26, no. 4, pp. 961-974, 2009.

[10] C. Billington, V. Kapos, M. Edwards, S. Blyth, and S. Iremonger, Estimated Original Forest Cover Map: A First Attempt, World Conservation Monitoring Center: Cambridge, 1996.

[11] N. Ramankutty, L. Graumlich, F. Achard et al., "Global land-cover change: Recent progress, remaining challenges," in Land-Use and Land-Cover Change: Local Processes and Global Impacts, E. F. Lambin and H. Geist Eds. New York: Springer, 2006, pp. 9-41.

[12] FAO, Statistical Yearbook 2013: World Food and Agriculture, Rome: FAO 2013.

[13] Statistical Center of Iran, Iran Statistical Yearbook 2012, Tehran, Iran: SCI, 2012.

[14] FAO, Selected Indicators of Food and Agricultural Development in the Asia-Pacific Region 1999-2009, Rome, Italy: FAO, 2010. 
[15] H. Azadi and A. A. Barati, "Agricultural land conversion drivers in northeast Iran," LDPI Working Paper, United Kingdom: The Land Deal Politics Initiative, 2013.

[16] J. J. Zhang, M. C. Fu, H. Zeng, Y. H. Geng, and F. P. Hassani, "Variations in ecosystem service values and local economy in response to land use: A case study of Wu'an, China," Land Degradation \& Development, vol. 24, no. 3, pp. 236-249, 2013.

[17] M. S. Wyman and T. V. Stein, "Modeling social and land-use/land-cover change data to assess drivers of smallholder deforestation in Belize," Applied Geography, vol. 30, no. 3, pp. 329-342, 2010

[18] E. C. Wood, G. G. Tappan, and A. Hadj, "Understanding the drivers of agricultural land use change in south-central Senegal," Journal of Arid Environments, vol. 59, no. 3, pp. 565-582, 2004.

[19] P. H. Verburg, D. B. van Berkel, A. M. van Doorn, M. van Eupen, and H. A. R. M. van den Heiligenberg, "Trajectories of land use change in Europe: A model-based exploration of rural futures," Landscape Ecology, vol. 25, no. 2, pp. 217-232, 2010.

[20] P. H. Verburg, M. D. A. Rounsevell, and A. Veldkamp, "Scenario-based studies of future land use in Europe," Agriculture, Ecosystems \& Environment, vol. 114, no. 1, pp. 1-6, 2006.

[21] P. Serra, X. Pons, and D. Sauri, "Land-cover and land-use change in a Mediterranean landscape: A spatial analysis of driving forces integrating biophysical and human factors," Applied Geography, vol. 28, no. 3, pp. 189-209, 2008.

[22] M. D. A. Rounsevell, F. Ewert, I. Reginster, R. Leemans, and T. R. Carter, "Future scenarios of European agricultural land use: II projecting changes in cropland and grassland," Agriculture Ecosystems \& Environment, vol. 107, no. 2-3, pp. 117-135, 2005.

[23] A. Mottet, S. Ladet, N. Coqué, and A. Gibon, "Agricultural land-use change and its drivers in mountain landscapes: A case study in the Pyrenees," Agriculture, Ecosystems \& Environment, vol. 114, no. 2-4, pp. 296-310, 2006.

[24] A. M. Hersperger and M. Bürgi, "Driving forces of landscape change in the urbanizing limmat valley, Switzerland," in Modelling Land-Use Change Progress and Applications, E. Koomen, J. Stillwell, A. Bakema, and H. J. Scholten Eds. Dordrecht: Springer, 2007, pp. 45-60.

[25] J. R. Mahoney, R. H. Moss, D. M. Allen et al., "Strategic plan for the climate change science program," U.S. Climate Change Science Program and Subcommittee on Global Change Research, Washington D.C., 2003, pp. 211.

[26] S. Mudgal, P. Benito, and E. Koomen, "Modelling of EU land-use choices and environmental impacts - Scoping study," BIO Intelligence Service \& SPINLAB, Vrije Universiteit, Amsterdam 2008.

[27] R. G. C. Scholte, C. C. Freitas, L. V. Dutra, R. J. P. S. Guimaraes, S. C Drummond, G. Oliveira, and O. S. Carvalho, "Utilizing environmental, socioeconomic data and GIS techniques to estimate the risk for ascariasis and trichuriasis in Minas Gerais, Brazil," Acta Tropica, vol. 121, no. 2, pp. 112-117, 2012.

[28] S. Barca, "Socioecological transitions and global change," Environmental Innovation and Societal Transitions, vol. 2, pp. $118-119,2012$

[29] K. Ronneberger, R. S. J. Tol, and U. A. Schneider, "KLUM: A simple model of global agricultural land use as a coupling tool of economy and vegetation," Working Paper FNU-65, Germany: Hamburg University and Centre for Marine and Atmospheric Science, 2005, p. 42.

[30] J. H. Farrington, T. Kuhlman, D. S. Rothman, Z. Imrichova, R. S. Reid, and É. K. Gyuró, "Reflections on social and economic indicators for land use change," in Sustainability Impact Assessment of Land Use Changes, K. Helming, M. Pérez-Soba, and P. Tabbush, Eds. Heidelberg: Springer, 2008, pp. 326-347.

[31] K. Helming, K. Tscherning, B. König et al., "Ex ante impact assessment of land use changes in European regions - The SENSOR approach," in Sustainability Impact Assessment of Land Use Changes,
K. Helming, M. Pérez-Soba, and P. Tabbush, Eds. Heidelberg Springer, 2008, pp. 77-105.

[32] T. Litman, Evaluating Transportation Land Use Impacts: Considering the Impacts, Benefits and Costs of Different Land Use Development Patterns, Canada Victoria Transport Policy Institute, 2011, pp. 1-62

[33] S. Petit, F. P. Vinther, P. J. Verkerk et al., "Indicators for environmental impacts of land use change across Europe," in Sustainability Impact Assessment of Land Use Changes, K. Helming, M. Pérez-Soba, and P. Tabbush, Eds. Heidelberg: Springer, 2008, pp. 305-324.

[34] S. Petit and P. Frederiksen, "Modelling land use change impacts for sustainability assessment," Ecological Indicators, vol. 11, no. 1, pp. $1-3,2011$.

[35] H. A. Linstone and M. Turoff, The Delphi Method: Techniques and Applications, Addison-Wesley Reading, MA, 1975.

[36] R. A. Krueger and M. A. Casey, A Practical Guide for Applied Research, SAGE Publications, Inc, 2000.

[37] M. Rivera, Practical and Guide to Thesis and Dissertation Writing, Quezon City: Katha Publishing Inc., 2007.

[38] H. Azadi, P. Ho, and L. Hasfiati, "Agricultural land conversion drivers: A comparison between less developed, developing and developed countries," Land Degradation \& Development, vol. 22, no. 6, pp. 596-604, 2011.

[39] K. G. Jöreskog and D. Sörbom, Lisrel-8 (User's Manual), Chicago: Scientific Software, 1993.

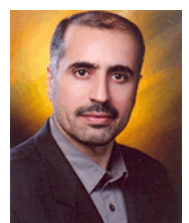

Ali Asadi was born in Iran in 1968. He is a professor in agricultural extension \& development. He is a faculty member in the Department of Agricultural Development \& Management, Faculty of Agricultura Economics \& Development, College of Agriculture \& Natural Resources, University of Tehran, Iran.

$\mathrm{He}$ is the dean of Faculty of Agricultural Economics \& Development from 2012.

Prof. Asadi has published several books and papers in the field of agricultural extension \& rural development.

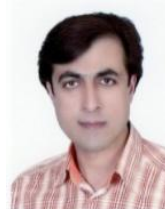

Ali Akbar Barati was born in Iran in 1975. He is a $\mathrm{Ph} . \mathrm{D}$. in agricultural development. He graduated in 2014 from the Department of Agricultural Development \& Management, Faculty of Agricultural Economics \& Development, College of Agriculture \& Natura Resources, University of Tehran, Iran.

Now he is a researcher in the field of agricultural land use change and agricultural development.

Dr. Barati has published some papers about agricultural land use changes in English and Persian languages.

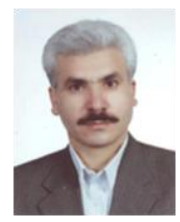

Khalil Kalantari was born in Iran in 1964. He is a professor in regional planning. He is a faculty member in the Department of Agricultural Development \& Management, Faculty of Agricultural Economics \& Development, College of Agriculture \& Natural Resources, University of Tehran, Iran.

$\mathrm{He}$ is the deputy dean in finance \& administration of Faculty of Agricultural Economics \& Development from 2013.

Prof. Kalantari has published several books and papers in the field of regional planning, development and regional modeling. 